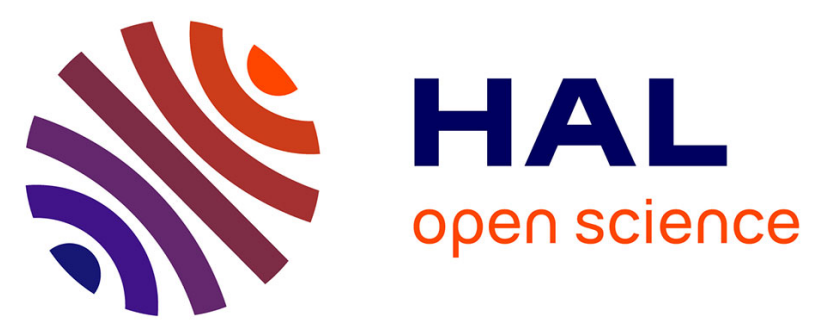

\title{
Integration of electrochemical impedance spectroscopy functionality in proton exchange membrane fuel cell power converter
}

Daniel Depernet, Abdellah Narjiss, Frédéric Gustin, Daniel Hissel, Marie-Cécile Péra

\section{To cite this version:}

Daniel Depernet, Abdellah Narjiss, Frédéric Gustin, Daniel Hissel, Marie-Cécile Péra. Integration of electrochemical impedance spectroscopy functionality in proton exchange membrane fuel cell power converter. International Journal of Hydrogen Energy, 2016, 41 (11), pp.5378-5388. 10.1016/j.ijhydene.2016.02.010 . hal-02130953

\section{HAL Id: hal-02130953 \\ https://hal.science/hal-02130953}

Submitted on 21 Oct 2021

HAL is a multi-disciplinary open access archive for the deposit and dissemination of scientific research documents, whether they are published or not. The documents may come from teaching and research institutions in France or abroad, or from public or private research centers.
L'archive ouverte pluridisciplinaire HAL, est destinée au dépôt et à la diffusion de documents scientifiques de niveau recherche, publiés ou non, émanant des établissements d'enseignement et de recherche français ou étrangers, des laboratoires publics ou privés. 


\title{
Integration of electrochemical impedance spectroscopy functionality in proton exchange membrane fuel cell power converter
}

\author{
Daniel Depernet ${ }^{a, b, *}$, Abdellah Narjiss ${ }^{c}$, Frédéric Gustin ${ }^{\text {a,d }}$, \\ Daniel Hissel $^{\text {a,d }}$, Marie-Cécile $\mathbf{P}$ era $^{\text {a,d }}$ \\ ${ }^{a}$ FCLAB Research Federation, FR CNRS 3539, FEMTO-ST/Energy Department, UMR CNRS 6174, UBFC, France \\ ${ }^{\mathrm{b}}$ University of Technology of Belfort-Montb'eliard, 90010 Belfort Cedex, France \\ ${ }^{c}$ ElecSys France, Engineering and Innovation Consulting, 25460 Etupes, France \\ 'University of Franche-Comt'e, 90010 Belfort Cedex, France
}

\begin{abstract}
This paper presents a solution of implementation of electrochemical impedance spectroscopy (EIS) functionality in the power converter used for Proton Exchange Membrane Fuel Cell (PEMFC) power management. The fuel cell is electrically coupled to an electric vehicle DC bus using a DC/AC/DC converter based on an inverter stage, a high frequency power transformer stage, and a rectifier stage. The EIS is achieved by the power converter in order to be performed without additional hardware, cost and volume. The proposed EIS process is integrated in the power control to allow real time using of EIS results for embedded diagnosis or control improvement. An experimental platform developed in the laboratory has validated the online EIS method on a $750 \mathrm{~W} 20$-cell-stack. Experimental validation tests presented in this paper illustrate spectral impedance monitoring for variations of requested current, air humidification rate and hydrogen flow rate.
\end{abstract}

\section{Introduction}

The conversion of hydrogen into electricity allows considering electric vehicles with an acceptable autonomy thanks to embedded storage of hydrogen [1], while enjoying all the benefits of powertrain electrification: greater energy efficiency, lower maintenance costs, zero emissions at the vehicle level. The PEMFC is one of the innovative key components of this energy conversion architecture. Its operating conditions are quite suitable for this type of application. Its efficiency, its cost and its reliability are decisive to the commercial growth of this technology and have not yet reached sufficient levels to make it profitable and competitive. Nowadays, considering the use of a PEMFC in an electric vehicle under actual operating conditions, it is possible to achieve a lifespan of about $2500 \mathrm{~h}$, while $5000 \mathrm{~h}$ is classically the requirement for personal vehicles. Thus, among the

* Corresponding author. University of Technology of Belfort-Montbéliard, 90010 Belfort Cedex, France. Tel.: +33 (0) 384583610 ; fax: +33 (0) 384583636 .

E-mail address: daniel.depernet@utbm.fr (D. Depernet). 
different ways to solve this technological bolt, the development of efficient real-time observation methodologies for the state-of-health of the fuel cell stack is key possibility. This could offer a better understanding of the phenomena causing internal damage and aging. Moreover, these technologies, if featuring real-time ability, should eventually help correcting the electrical and fluidic management of fuel cell system in order to minimize the degrading effects.

The use of PEMFC in automotive vehicles also makes diagnostic and maintenance operations very expensive and difficult to implement without the intervention of a specialist. These operations can then become very restrictive for the user. The development of smart characterization methods that are online, incorporated and low cost is essential for in situ diagnosis of PEMFC system. Therefore, the vehicle should be able to ensure its diagnosis autonomously, generating the lowest possible downtime. In addition, the extra cost and integration constraints implied by the implementation of these features should remain low since these two properties already appear as penalizing factors whose impact needs to be reduced [2].

Accurate identification of the parameters of the fuel cell stack \& system will supply diagnostic algorithms with more reliable data and will help facilitating decision in the case of a default event [3]. It will also achieve an optimal management of control leading to increased service life of the fuel cell stack.

After describing the principle of the PEMFC connection to the DC bus of the vehicle, the structure of the power converter based (here) on a HF transformer will be described. Then, the power converter control principle will be presented. The constraints of implementation of the PEMFC characterization by EIS will also be given. The integration principle of EIS ability thanks to power converter control will then be shown. Finally, the experimental system developed in the laboratory and experimental results illustrating the online characterization of PEMFC will be highlighted before concluding.

\section{PEMFC coupling to electrical vehicle DC bus}

PEM fuel cells have the property of being low voltage and high current power sources. Indeed, the cell voltage depends on the required current. The experimental single-cell voltage is classically comprised between $0.4 \mathrm{~V}$ and $1 \mathrm{~V}$. The 20-cell experimental stack UBZM 750 used in this study has a voltage that remains between approximately $20 \mathrm{~V}$ (no-load) and $13 \mathrm{~V}$ (for rated current). The specification of the intended application defines a vehicle DC bus voltage about 8 times higher than the voltage of our considered PEMFC stack (note that this elevation ratio is quite classical on embedded applications). The experimental DC output voltage of the converter is set at $110 \mathrm{~V}$ to keep this specified voltage boost from UBZM-750 stack voltage. Power increasing may then be obtained by coupling several stacks, thereby also increasing the power availability on-board the vehicle in case of failure of one of the fuel cell stacks.

The power converter coupling the fuel cell stack to the vehicle DC bus must perform this high voltage elevation ratio while minimizing also the energy losses due to power conversion. Electronic topology of the power converter is shown in Fig. 1a and discussed in Ref. [4]. The first stage consists of a full bridge MOSFET inverter coupled to the PEMFC via a high frequency capacitor filter. This capacitive input filter reduces the harmonic content of the requested current which may be harmful for the PEMFC [5]. A temporized charge circuit allows the capacitor $C$ to be connected to PEMFC without current overload. The high switching frequency of the transistors implies the need for special attention to the quality of MOSFET switching to limit their losses. The second stage includes a PLANAR technology high frequency transformer. Its main asset is its very small size (high power density) mainly due to the use of high frequency (i.e. up to $150 \mathrm{kHz}$ ) voltage and current combined with its low eddy current loss level (its efficiency is typically $98 \%$ ). This property helps converter integration constraints in the vehicle to be minimized [6]. The transformer also provides galvanic isolation which may be useful in some applications. It performs a high voltage elevation ratio by simple design of the ratio between turn numbers of primary and secondary windings. PLANAR transformers may be used for powers up to $20 \mathrm{~kW}$, which is an acceptable limit for applications in hybrid electric traction when the power is correctly segmented (i.e. the use of multiple low-power fuel cell power generation units). The third stage consists in a diode rectifier and a LC low-pass filter which reduces the harmonic content before connection to the vehicle DC bus. Limiting losses in this stage can be met by choosing diodes characterized by a low voltage drop. Efficiency improvement according power domain of this converter including Silicon Carbide components is discussed in Ref. [7].

Control of energy transfer is performed by a motor control Digital Signal Processor (DSP). This microcontroller supports control of power semiconductors, measurements and regulations. It is also used to perform the characterization of the PEMFC by EIS presented in this paper, as shown in Fig. 2. Using of a single microcontroller for control and characterization allows size and cost to be minimized. Furthermore, the entire dynamic of the control and of the sampling may be used by real time algorithms to perform EIS measurements. The curves of Fig. 1b illustrate the control signals of the inverter MOSFET and the electrical waveforms. The principle is to drive the transistors to achieve a symmetrical AC waveform across the primary of the transformer $\mathrm{V}_{\mathrm{p}}$. The switching frequency $F_{\mathrm{PWM}}$ is chosen equal to $50 \mathrm{kHz}$, which is the lowest limit considering the HF technology of the transformer. The increase in PWM frequency would facilitate the design of the filters and increase the accuracy of the EIS, but at the expense of increased losses in the inverter.

Frequency of primary voltage $V_{p}$ is fixed while its RMS value is controlled by acting on the conduction duration of the transistors which is modeled by the duty cycle $\alpha$. Gates of transistors $Q_{1}$ and $Q_{2}$ are controlled with identical signals in order to perform the adjustment of the conduction time during the positive halfwave of the transformer primary voltage $V_{p}$. Transistors $Q_{3}$ and $Q_{4}$ are controlled identically, but for adjustment of the conduction time during the negative halfwave of $V_{p}$. The average value of the output voltage of the converter $V_{\mathrm{BUS}}$ is linked to the PEMFC voltage $V_{\mathrm{FC}}$ by the voltage ratio $m$ of the transformer and the duty cycle $\alpha$ according to the following expression:

$V_{\mathrm{BUS}}=2 m \alpha V_{\mathrm{FC}}$ 


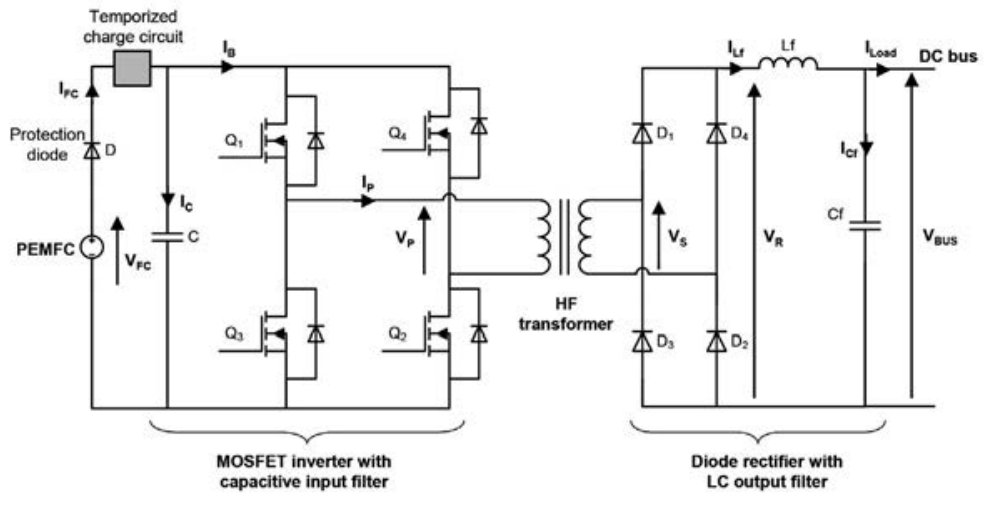

(a)

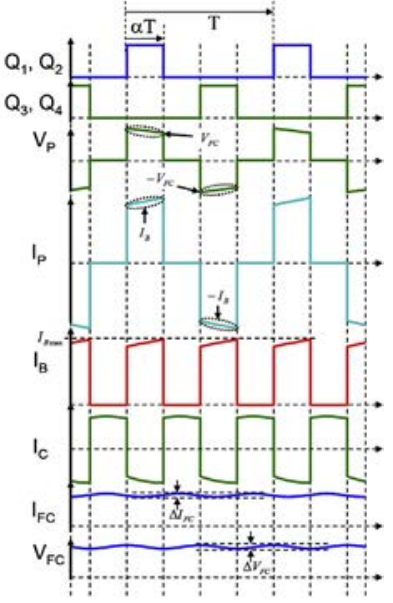

(b)

Fig. 1 - Power converter. (a) Topology. (b) Control signal and fuel cell electrical waveforms.

Current ripple $\Delta \mathrm{I}_{\mathrm{FC}}$ and voltage ripple $\Delta \mathrm{V}_{\mathrm{FC}}$ in the fuel cell are due to switching of power converter MOSFETs. They depend on the switching frequency $F_{\mathrm{PWM}}$, on the internal impedance of the fuel cell, and on the capacitance $C$ of the input filter. Similarly, the current ripple of $I_{L f}$ in the inductor $L_{f}$ and output voltage ripple are linked to the switching frequency, to the impedance characteristics of the load and to the values of $L_{\mathrm{f}}$ and $C_{\mathrm{f}}$. Choosing a high switching frequency (typically $\geq 50 \mathrm{kHz}$ ) limits the size of input and output filters.

\section{Characterization methods of PEMFC}

\section{Interests of characterization}

PEMFC is among the shorter lifetime components of the fuel cell electric vehicle. It's aging depends mostly on the conditions of use that are related to the availability of the energy stored in the power sources which are associated with, the type of control and the behavior of the driver [8]. It also depends on external conditions such as temperature, which can reach extreme value depending on geographical location and cooling conditions. PEMFC is also sensitive to the presence of contaminants in the gas which can cause damage [9-11]. As examples, hydrogen sulphide $\left(\mathrm{H}_{2} \mathrm{~S}\right)$ is naturally present in the environment and also produced by chemical industry. It causes irreversible damage and premature aging of the fuel cell [12-14]. Carbon monoxide (CO) is also present in the environment and causes reversible PEMFC damage [15]. Its progressive accumulation within the fuel cell requires the implementation of cleaning strategies to recover the initial performances [16].

Given the pressing need to reduce the cost of fuel cell electric vehicles and the need to increase the availability of electric vehicles, low-cost solutions to extend the source lifetime and support their maintenance are required. The method presented here to characterize the PEMFC is nonintrusive, doesn't need additional hardware and additional cost, and can assess PEMFC state of health in real time. A similar characterization strategy adapted to lead acid batteries controlled by boost converter is presented in Ref. [17].

\section{EIS of PEMFC}

Characterization of the PEMFC thanks to voltage and current monitoring has the advantage of being achievable by use of simple external voltage and current sensors giving it a nonintrusive nature. This functionality can often exploit the measurements of sensors naturally integrated in the control system, what allows the reduction of implementation cost. Many PEMFC diagnostic methods use EIS measurement. They can be based on the identification of a mathematical model [18] or on statistical properties [19]. The Nyquist diagram of the PEMFC electrochemical impedance considered in static

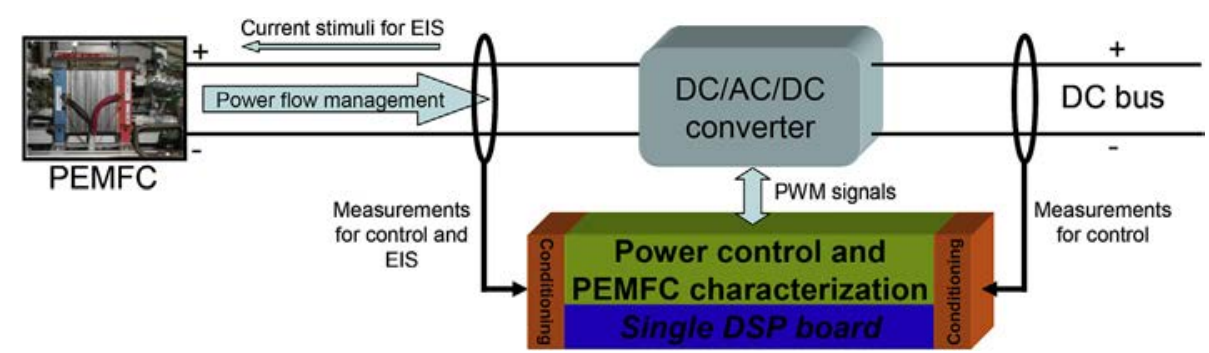

Fig. 2 - Principle of EIS integration in the power converter control. 
operation conditions is shown in Fig. 3a. The electrochemical phenomena can be separated by plotting the impedance as a function of frequency. The mass transport phenomenon is generally associated with low frequencies, and the charge transfer phenomenon is associated with the higher frequencies. Thus, EIS is appreciated for its ability to allow the analysis of the internal properties of the PEMFC.

To highlight the principle of integration of EIS functionality in power electronics, the simplified Randle model shown in Fig. $3 b$ of PEMFC is considered for simulation with Matlab/ Simulink software. The inductance $L$ models the inductive nature of the various electrical conductors of the stack. Its value is generally very low and sometimes overlooked. The resistance $R_{m}$ characterizes the conductivity of the electrolyte and in particular the ionic resistivity of the membranes. Phenomena that occur near the electrodes are characterized by the capacity $C_{\mathrm{dc}}$ related to double layer phenomenon, the resistance $R_{\mathrm{p}}$ related to charge transfer and the Warburg impedance $Z_{\mathrm{w}}$ related to diffusion phenomena induced by the production and consumption of species at interfaces [20].

\section{Integration of EIS functionality in power converter control}

\section{Adaptation of power management strategy}

EIS functionality is integrated in the DC/AC/DC converter used for coupling of PEMFC to the DC bus. The principle is to control the power converter to create an excitation current in the fuel cell and simultaneously perform synchronous measurement of the excitation current and voltage response to compute the impedance of the PEMFC for the excitation frequency under consideration. Repeating this principle for several frequencies selected to cover the width of relevant spectrum with sufficient precision will lead to Nyquist plot of the fuel cell impedance [21]. The electrical behavior of the PEMFC is not linear. PEMFC impedance spectrum depends on the operating point and also on many parameters such as gas flow rate or temperature. The current stimulus used to measure the impedance spectrum should thus be of very small amplitude around a fixed operating point to consider the behavior of the fuel cell as linear and as stationary as possible in this range of variation but high enough to achieve a sufficient signal-noise ratio [22].

Thus the implementation of the impedance measurement needs to maintain the PEMFC to a fixed operating point for the duration of the measurement. The PEMFC current must match to the desired value $I_{0}$ before the impedance measurement and will not participate in the control of the DC bus voltage during the impedance measurement. PEMFC is assumed to be a part of an hybrid architecture where other power sources such as batteries and ultracapacitors provide rapid current transients and lend higher dynamic performance to the powertrain [23]. These additional sources are needed to achieve DC bus voltage control by adaptation of power management during PEMFC EIS sequences. The amplitude of the PEMFC electrical excitation current will be controlled by the converter with low value compared to the rated current in order to maintain a linear behavior of the impedance. The PEMFC excitation principle presented further in this paper can be completed if output voltage $\mathrm{V}_{\mathrm{BUS}}$ is sufficiently stable during the EIS.

EIS process should not disrupt the continuity of service of electric vehicle [24]. Particularly, DC bus voltage $V_{\text {Bus }}$ should remain inside the acceptable limits defined in the DC bus specifications. Keeping the PEMFC current at the constant value $I_{0}$ requires adapting of the current reference of other sources (battery and ultracapacitors) in order to satisfy the current needed for DC bus voltage control. Different control strategies can be adopted according to the behavior of the hybrid system:

(1) $V_{\text {BUS }}$ voltage remains within the allowed range and its variations don't significantly interfere the PEMFC current $I_{0}$ : EIS can be completed. This case corresponds to the ability of the batteries and supercapacitors to control the DC bus voltage during the EIS. This ability depends on the design of the sources coupled to DC bus with the PEMFC, the PEMFC current value $I_{0}$, the vehicle power demand and the duration of the measurement of the impedance spectrum (which should be as limited as possible).

(2) DC bus voltage variations are not acceptable: decoupling of the PEMFC from DC bus voltage control loop can no longer satisfactorily control the powertrain. The EIS process is then suspended and the PEMFC is reconnected to the DC bus control loop. This case occurs for high load transients or when maximum or minimum state of charge of batteries or ultracapacitors occurs. Regarding this operating case, it must be underlined that the need of evaluating the actual state-of-health of the fuel cell stack is not a permanent task. This state-of-

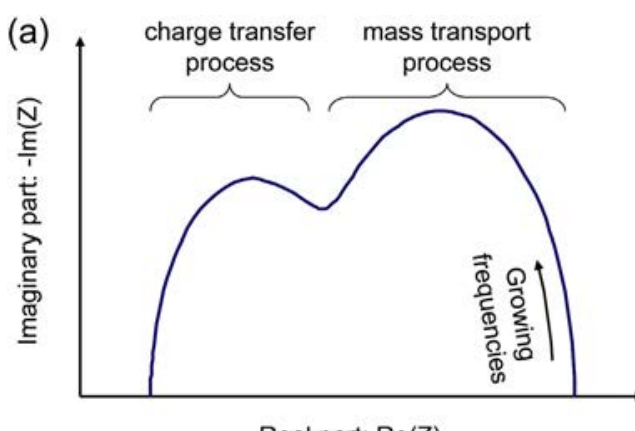

Real part: $\operatorname{Re}(Z)$

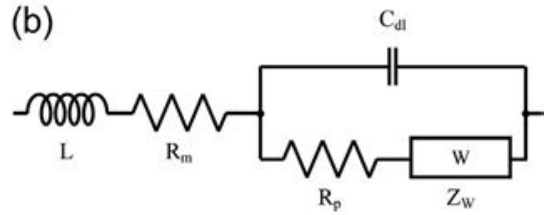

Fig. 3 - PEMFC impedance. (a) Typical Nyquist diagram. (b) Simplified Randle model. 
health could be evaluated, from time to time, when the DC bus is well-managed.

These strategies highlight the interest of minimizing the duration of the PEMFC EIS process to increase its viability in the power control. The ability to perform EIS at the same time as power control makes possible real time diagnosis strategies based on EIS results such as that presented in Ref. [25]. The block diagram of Fig. 4 illustrates the various phases of implementation of the PEMFC EIS process.

These phases are described as follows:

(1) $\mathrm{V}_{\mathrm{BUS}}$ voltage is controlled according to the control principle. PEMFC current is defined by the control loop of DC bus voltage.

(2) PEMFC current reference is set to $I_{0}$, which is defined by EIS specifications. Current control is active until PEMFC current will be stabilized to $I_{0}$ value. At the same time calibration of $I_{F C}$ and $V_{F C}$ measurements is done to maximize the measurement accuracy of current stimulus and voltage response, which have low amplitude compared to the average values of $I_{\mathrm{FC}}$ and $\mathrm{V}_{\mathrm{FC}}$. This fully automated feature is described below.

(3) Current control to $I_{0}$ is disabled to avoid interference with stimulus control necessary for EIS. Then, EIS begins by successive excitations of the PEMFC at different frequencies in order to build the Nyquist diagram of impedance. The stimuli are defined to meet the desired frequencies and amplitudes. This functionality described below uses current and voltage calibrated measures. Current stimuli and voltage responses measurements are used to determine the PEMFC impedance for every frequency of the whole spectrum. A time delay may be inserted between the measures to warrant stabilization of the stimuli at each change of excitation frequency if necessary. Data are then transmitted to an external processing unit and displayed on a graphical user interface (GUI). After the last EIS measurement, the PEMFC current reference is again connected to the DC bus voltage control loop to return to normal operation (phase 1).

\section{Analog calibration of measures}

For a fixed operating point, the PEMFC can be modeled as an electromotive force $E_{0}$ in series with the impedance $Z_{\mathrm{FC}}$. The PEMFC harmonic impedance $Z_{\mathrm{FC}}(f)$ at frequency $f$ is determined from the AC components at frequency fof the current $I_{Z}(f)$ in $Z_{F C}$ and the voltage $V_{Z}(f)$ across $Z_{F C}$ using the following equation:

$Z_{F C}(f)=\frac{V_{Z}(f)}{I_{Z}(f)}$

The current stimulus and voltage response used to determine the impedance are low compared to the average values of fuel cell current and voltage. These quantities are not physically accessible and must be extracted from the measurement of total PEMFC electrical quantities $I_{\mathrm{FC}}$ and $\mathrm{V}_{\mathrm{FC}}$. Calibration of measurable $I_{\mathrm{FC}}$ and $\mathrm{V}_{\mathrm{FC}}$ is needed to maximize

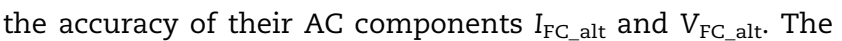
electronic calibration is controlled by the microcontroller used for power control and EIS to adjust the offsets to the PEMFC operating point as shown in Fig. 5a. Gain are fixed and calculated according the PEMFC impedance and the expected AC amplitudes.

The electronic circuit is designed to create an offset in order to electronically compensate the average value of the current and the voltage. Calibration of current and voltage measurements is achieved by two identical electronic circuits. Two PWM outputs combined with low pass filters operate as digital to analog converters (DAC) to adjust the offsets of current and voltage sensor outputs. The combination of these adjustable offsets with analog gains and differential amplifiers perform the calibration of $\mathrm{AC}$ component $\mathrm{I}_{\mathrm{FC} \_ \text {alt }}$ and $\mathrm{V}_{\mathrm{FC} \_ \text {alt }}$ within the input voltage range $[0 ; 3.3 \mathrm{~V}]$ of the integrated analog to digital converter (ADC) module of the microcontroller. As previously mentioned these offset adjustments are performed during the polarization phase of the PEMFC at current $I_{0}$ and before EIS measurements. As illustrated in Fig. 5b, the calibration principle is based on the offset control to match the measure to the zero axes of the AC component by acting on the PWM duty cycle and then on the DAC output. When the calibration is completed and the

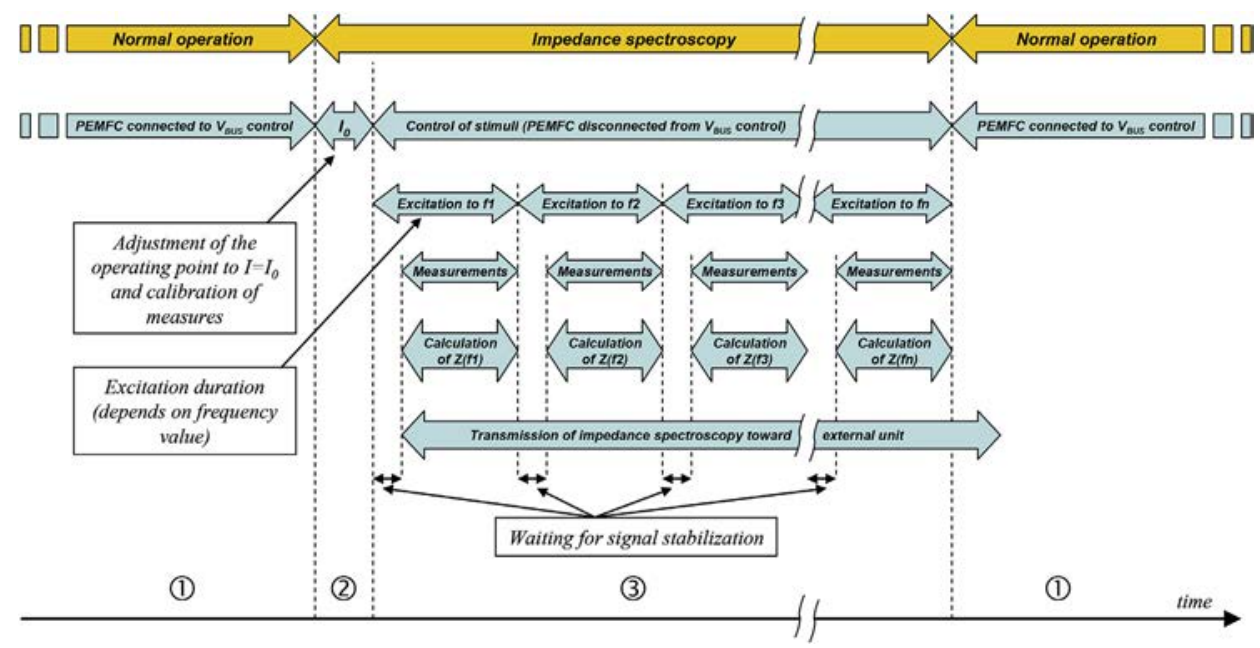

Fig. 4 - Integration principle of EIS inside power control. 

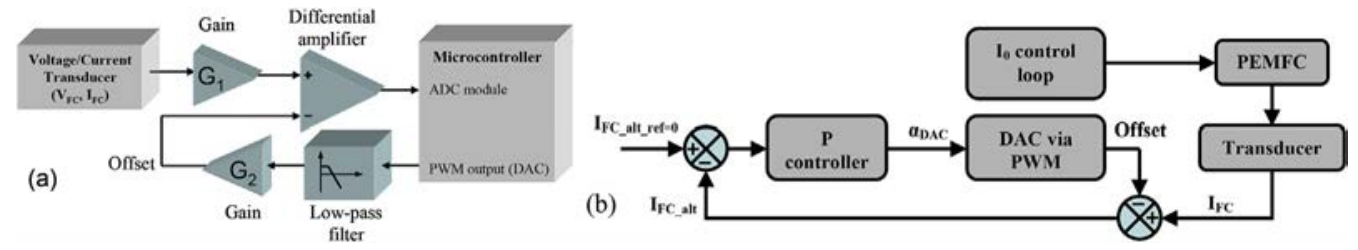

Fig. 5 - Calibration principle. (a) Functional electronic circuit. (b) Current offset compensation control loop.

desired current $I_{0}$ is stable, the calibration process is disabled to perform EIS measurements. Calibrations of $I_{\mathrm{FC} \_a l t}$ and $V_{\mathrm{FC} \_ \text {alt }}$ follow the same principle at the same time.

\section{Principle of PEMFC stimulation}

The principle of PEMFC stimulation consists in controlling the current stimulus $I_{\mathrm{FC} \text { alt }}$ around the polarization current $I_{0}$ as shown in Fig. 6. Amplitude $A_{i}$ and frequency $F_{i}$ of the current stimulus are defined by the wave form of the AC reference

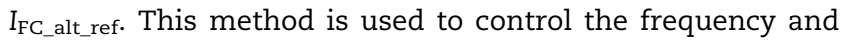
amplitude of current stimulus while keeping in the linearity range the PEMFC behavior. The calibrated measurement of the current is the feedback of the stimulation current control loop. The output of the proportional controller defines a variation $d \alpha$ of the duty cycle around the value $\alpha_{0}$ previously determined to achieve the operating point represented by the current $I_{0}$. The number of periods of excitation is set to make a compromise between the accuracy of the digital signal processing, the computational load, and the measurement time of the spectrum. The total measurement time of Nyquist diagram is mainly defined by the measurement time of low frequency stimuli.

\section{Principle of impedance measurement}

The current and voltage sampling must be made with a special attention because of the possible high harmonic disturbances caused by the high frequency switching of the power converter. PEMFC current ripple due to converter switching mainly depends on the value of the capacitance $C$ of the input filter and the switching frequency. The pseudoFourier series development of the signal shows that the spectrum consists of a main harmonic at twice the switching frequency $2 F_{\mathrm{PWM}}$ and harmonic groups with lower amplitudes and spaced on both sides of $2 F_{\mathrm{PWM}}$ of a multiple of the excitation frequency $F_{\mathrm{i}}$. These harmonics are naturally present in analog signals after calibration of fuel cell current and voltage depending on the sensors and calibration circuit bandwidth.

The highest harmonic caused by converter switching may have a large amplitude compared to the stimulus amplitude and can affect the measurement accuracy of the relevant spectral components of EIS. The filtering principle eliminates disturbances due to power converter switching. A partial anti-aliasing filtering attenuates harmonics above the Nyquist frequency $F_{\mathrm{e}} / 2$ where $F_{\mathrm{e}}$ is the sampling frequency. Analog inputs of ADC module may include a residual harmonic content at frequency $2 \mathrm{~F}_{\mathrm{PWM}}$ considering the high amplitude of the harmonic at this frequency before filtering. Synchronizing the sampling frequency with the switching frequency $\left(F_{\mathrm{e}}=F_{\mathrm{PWM}}\right)$ locks aliasing of every multiple components of $F_{\mathrm{PWM}}\left(F_{\mathrm{PWM}}, 2 F_{\mathrm{PWM}}, 3 F_{\mathrm{PWM}}, \ldots\right)$ onto the zero frequency axis. The relevant spectral component of the stimulus required to measure the impedance is thus protected from any aliasing risk since they are concentrated in the DC component of the spectrum obtained after sampling. This method eliminates interference caused by the power converter whatever the switching frequency and facilitates the design of anti-aliasing filters.

The simulation curves of Fig. 7 illustrate the different steps of measuring the PEMFC excitation current and its voltage response. Fig. 7a illustrates the PEMFC current and voltage obtained for a polarization current $I_{0}=25 \mathrm{~A}$. The mean value of these signals is combined with a high frequency variation at $2 F_{\mathrm{PWM}}\left(F_{\mathrm{PWM}}=50 \mathrm{kHz}\right)$ due to the power converter switching and a low frequency variation corresponding to the EIS stimulus $\left(F_{i}=500 \mathrm{~Hz}\right.$ and $\left.A_{i}=0.45 \mathrm{~A}\right)$. Fig. $7 \mathrm{~b}$ shows the effect of synchronization of current sampling with the frequency $F_{\mathrm{PWM}}$. The sampled signal is then decimated by a decimation factor $D$ in order to keep a constant phase resolution regardless of the excitation frequency. Then, the factor $D$ depends on the

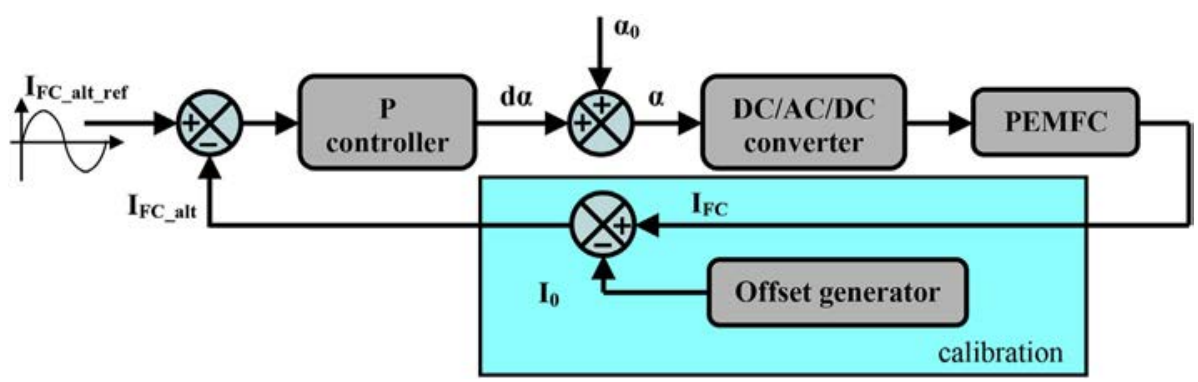

Fig. 6 - Principle of PEMFC current stimulation. 
(a)

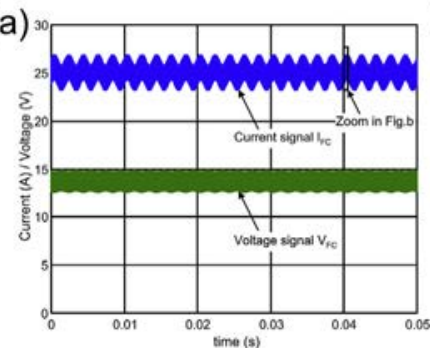

(b)

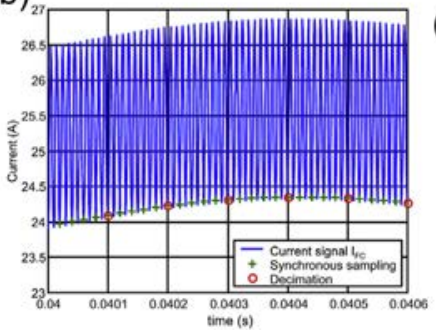

(c)

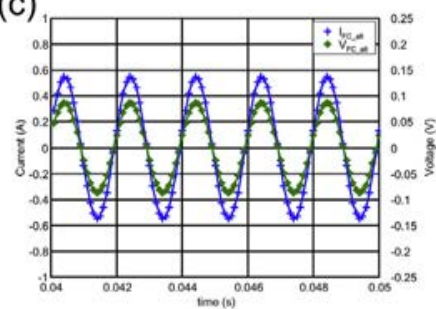

Fig. 7 - Measurement principle of PEMFC excitation signals with $\mathrm{I}_{0}=25 \mathrm{~A}, \mathrm{~F}_{\mathrm{PWM}}=50 \mathrm{kHz}, \mathrm{F}_{\mathrm{e}}=50 \mathrm{kHz}, \mathrm{F}_{\mathrm{i}}=500 \mathrm{~Hz}$, $A_{i}=0.45 \mathrm{~A}, \mathrm{D}=5$. Randle model parameters: $\mathrm{L}=1 \mu \mathrm{H} ; \mathrm{R}_{\mathrm{m}}=160 \mathrm{~m} \Omega ; \mathrm{R}_{\mathrm{p}}=90 \mathrm{~m} \Omega ; \mathrm{C}_{\mathrm{dl}}=150 \mathrm{mF} ; \mathrm{Z}_{\mathrm{W}}=1 \Omega$. Input filter parameter: $\mathrm{C}=62.5 \mu \mathrm{F} ; \mathrm{L}_{\mathrm{f}}=1 \mathrm{mH} ; \mathrm{C}_{\mathrm{f}}=10 \mu \mathrm{F}$ (a) PEMFC current and voltage. (b). Synchronous sampling and decimation. (c) Results after calibration, sampling and decimation.

EIS frequency. In this example $D=5$ in order to extract $S P=20$ samples per stimulus period what corresponds to a phase angular resolution of $18^{\circ}$. Identical measurement methods are implemented for current and voltage sampling. Fig. 7c shows the actual result which combines calibration, sampling and decimation effects.

The frequency domain of the impedance spectrum is defined by the following equation:

$\frac{F_{P W M}}{D \cdot S P} \leq F_{i} \leq \frac{F_{P W M}}{S P}$

Then, in the case of $F_{P W M}=50 \mathrm{kHz}$ and $S P=20$ samples per period, the maximum frequency of the spectrum can reach $2.5 \mathrm{kHz}$ while the minimum frequency can be as small as desired since $D$ is not limited.

Real and imaginary parts of current stimulus and voltage response signals are then extracted from the sampled data by Discrete Fourier Transform (DFT). This process is used in particular to obtain a very good precision on the phase and amplitude even in the presence of residual disturbances. The real and imaginary parts of $k$ rank harmonics of $I_{\mathrm{FC} \_a l t}$ and $V_{\text {FC_alt }}$ for a total of $N$ samples may be expressed as follows:

$$
\begin{aligned}
& \left\{\begin{array}{l}
\operatorname{Re}\left(\mathrm{I}_{\mathrm{FC} \_ \text {alt }}\right)=\frac{2}{N} \sum_{n=0}^{N-1} \mathrm{I}_{\mathrm{FC} \_ \text {alt }}(n) \cdot \cos (2 \pi k n / N) \\
\operatorname{Im}\left(I_{\mathrm{FC}_{-} \text {alt }}\right)=-\frac{2}{N} \sum_{n=0}^{N-1} I_{\mathrm{FC} \_ \text {alt }}(n) \cdot \sin (2 \pi k n / N)
\end{array}\right. \\
& \left\{\begin{array}{l}
\operatorname{Re}\left(V_{F_{-} \text {alt }}\right)=\frac{2}{N} \sum_{n=0}^{N-1} V_{F_{-} \text {alt }}(n) \cdot \cos (2 \pi k n / N) \\
\operatorname{Im}\left(V_{F_{-} \text {alt }}\right)=-\frac{2}{N} \sum_{n=0}^{N-1} V_{F_{-} \text {alt }}(n) \cdot \sin (2 \pi k n / N)
\end{array}\right.
\end{aligned}
$$

Only the rank $k$ of the relevant spectral component which corresponds to the stimulus frequency is needed for determining the impedance at this frequency. It is defined as the number of measuring periods taken into account in the DFT formula. The real and imaginary parts are calculated over sampling. Impedance for the right frequency is then deduced from the complex expressions of current and voltage:

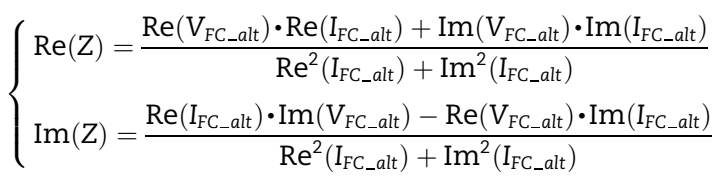

\section{Experimental results}

\section{Presentation of the experimental set}

The experimental set consists of a fuel cell UBZM 750 connected to the air and hydrogen feeding circuits, water cooling system and monitoring instruments of the fuel cell laboratory testing platform. The characteristics of the PEMFC are listed in Table 1. The power converter with integrated EIS is shown Fig. 8. Its rated power is $1 \mathrm{~kW}$ and the characteristics of the components are listed in Table 2.

The PEMFC is connected to the power converter via a protection circuit and a temporized charging circuit of the input filter capacitor $C$. The rectifier output is connected to a programmable dynamic load to emulate the power flow on the DC bus of the electric vehicle. The gates of the inverter MOSFETs are driven by fast drivers which can admit a switching frequency up to $100 \mathrm{kHz}$. Control and EIS algorithms are implemented into the $100 \mathrm{MHz}$ TMS320F2808 DSP controller from

\section{Table 1 - Characteristics of PEMFC UBZM 750.}

Cell number
Rated current
Rated power
Active surface
Operating temperature limits
Rated operating température
Rated air dew point
Operating pressure
Maximal anode/cathode pressure
$\quad$ differential
Anode feeding
Cathode feeding
Cooling fluid

\section{0}

$50 \mathrm{~A}$

$750 \mathrm{~W}$

$100 \mathrm{~cm}^{2}$

$20^{\circ} \mathrm{C}-65^{\circ} \mathrm{C}$

$55^{\circ} \mathrm{C}$

$45^{\circ} \mathrm{C}$

1.5 bar max

0.6 bar

$100 \%$ hydrogen Humidified air Demineralized water 


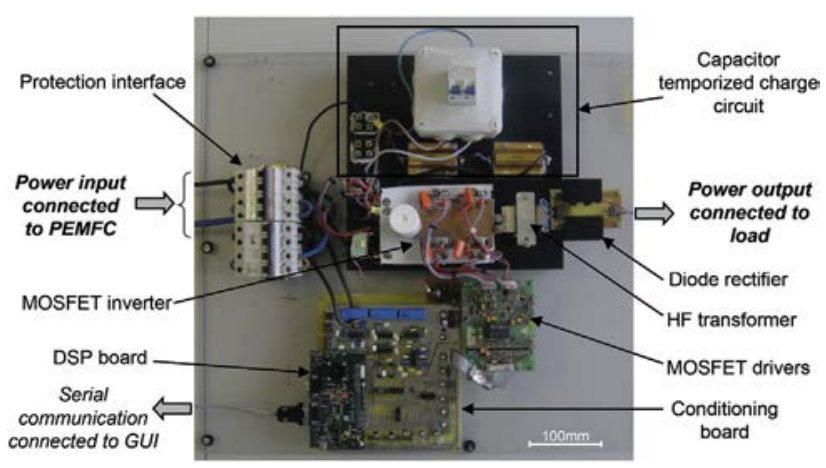

Fig. 8 - Power converter with integrated EIS. sampling by the DSP controller. The data of Fig. 9a are obtained for a stimulation frequency $F_{i}=500 \mathrm{~Hz}$. The ratio between the amplitude of the voltage and the current as well as their relative phase shift is representative of the PEMFC impedance. This experimental result is consistent with the simulation results presented in Fig. 7c for a theoretical PEMFC model close to the tested PEMFC. The curves of Fig. 9b are obtained for a stimulation frequency $F_{\mathrm{i}}=2 \mathrm{~Hz}$ and validate the reliability of the measuring principle also at low frequency. It may be noted in this case a high value of the decimation factor $D=1250$ which results in an identical angular resolution to that obtained for the excitation frequency of $500 \mathrm{~Hz}$. The number of samples per excitation period is set to 20 in this example and remains unchanged regardless of the excitation

Table 2 - Characteristics of DC/AC/DC power converter.

Inverter MOSFET: IXFN340N07

Transformer PAYTON 1 kW SMPS T250DC-1-12
$\mathrm{V}_{\mathrm{ds}}=70 \mathrm{~V}, \mathrm{Id}=340 \mathrm{~A}, \mathrm{R}_{\mathrm{dson}}=4 \mathrm{~m} \Omega, \mathrm{t}_{\mathrm{rr}}<250 \mathrm{~ns}$

$\mathrm{P}_{\max }=1 \mathrm{~kW}, \mathrm{~F}_{\max }=150 \mathrm{kHz}, \mathrm{V}_{\text {in }}=10-20 \mathrm{~V}, \mathrm{I}_{\text {in }}=117 \mathrm{~A}, \mathrm{~m}=12$, nominal

losses $=8.5 \mathrm{~W}$

$\mathrm{V}=400 \mathrm{~V}, \mathrm{I}=20 \mathrm{~A}, \mathrm{Vf}<1.05 \mathrm{~V}, \mathrm{t}_{\mathrm{rr}}<60 \mathrm{~ns}$
Texas Instruments. The main integrated peripherals used for this application are:

- Enhanced PWM modules: PWM outputs are used to adjust the duty cycle of the MOSFET control signals and thus to control the output voltage of the power converter and the PEMFC current for power management and stimulus.

- 12 bits ADC module (160 ns conversion time): it performs sampling of measures necessary for EIS and control.

- PWM generators used as DAC: Two PWM outputs combined with low-pass filters control analog outputs to perform calibration of current and voltage signal required for EIS.

- The SCI (Serial Communication Interface) controller: it is used to communicate with a data processing unit (computer). A GUI is developed to manage communications (high level control, storage and display of measures).

\section{Validation of PEMFC EIS}

Measurement of calibrated current and voltage

The curves of Fig. 9 illustrate the experimental measurement results of the current stimulus and voltage response after frequency. Each of these sets of measurements is treated by the DSP controller in a real time process to compute the impedance at the excitation frequencies.

\section{Measurement of impedance spectrum}

PEMFC EIS is achieved by sequencing impedance measurement for several relevant excitation frequencies. The frequency domain depends on the goals of the characterization. The frequency bounds, the number of frequency lines and the frequency values are set to extract the relevant information of the spectrum without penalizing the measurement time. The implementation of control and EIS algorithms follows a realtime multitask architecture. Then, sampling is not affected by the computation of the DFT or the transfer of the results to the GUI. DSP processing time can be neglected compared to acquisition time necessary to determine the full impedance spectrum. If the stabilization time between each frequency change is also neglected (cf. Fig. 4), the total measurement of an impedance spectrum can be assessed by the following equation:

$\mathrm{T}_{\text {spectrum }}=\sum_{i=1}^{\mathrm{Nf}} \frac{N_{\text {per }}}{F_{i}}$

Where $F_{i}$ are the stimulation frequencies of the PEMFC, $N_{\text {per }}$
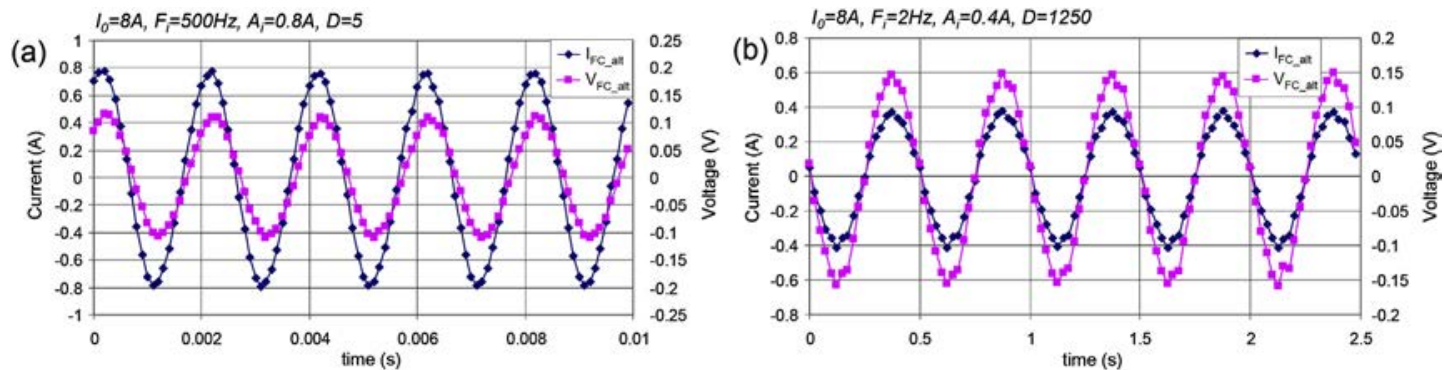

Fig. 9 - Measurements of PEMFC excitation current and voltage response. (a) $F_{i}=500 \mathrm{~Hz}$. (b) $F_{i}=2 \mathrm{~Hz}$. 
the number of measurement periods of each frequency line and $N_{\mathrm{f}}$ the number of frequency lines. Lower frequencies lines have the main contribution to the total time required to achieve EIS. In the example of a spectrum built with $N_{f}=28$ lines of frequencies between $2 \mathrm{~Hz}$ and $500 \mathrm{~Hz}$ and $N_{\text {per }}=5$, the total measuring duration is about $16 \mathrm{~s}$.

\section{Application to online measurement of impedance variations}

Several tests are performed to demonstrate the ability of the integrated EIS device to achieve the real time measurement of the PEMFC impedance in response to the evolution of electrical, fluidic or chemical parameters.

\section{Load current effect}

Interpretations of fuel cell impedance changes are not always easy due to the dependence on several test conditions and especially load current. This is why it is necessary to set and know the value of the PEMFC load current $I_{0}$ during EIS, to identify the parameters related to other phenomena than the variation of load current. Fig. 10 shows the location of the PEMFC impedance Nyquist diagram for two different values of load current $I_{0}=8 \mathrm{~A}$ and $12.2 \mathrm{~A}$. The curves illustrate a decrease of the impedance of the PEMFC when the current increases. This effect is especially remarkable for the low frequencies. In these tests, the hydrogen flow rate, PEMFC temperature, air humidity and hydrogen humidity are kept constant $\left(\mathrm{Q}_{\mathrm{H}_{2}}=5.47 \mathrm{slpm}\right.$ : hydrogen flow rate, $\mathrm{T}_{\mathrm{FC}}=48^{\circ} \mathrm{C}$ : PEMFC temperature, $\mathrm{RH}$ _air $=85 \%$ : relative humidity of air, and $\mathrm{RH}_{-} \mathrm{H}_{2}=20 \%$ : relative humidity of hydrogen).

\section{Air humidification rate effect}

PEMFC membrane must be humidified to provide an efficient proton exchange between the anode and the cathode [26]. The lack of water in the membrane causes a reduction of the ionic conductivity which then results in an increase of the ohmic voltage drop and therefore an increase of equivalent impedance of the PEMFC [27]. Membrane humidification is performed by adjusting the air humidification rate at the cathode inlet. Fig. 11 illustrates

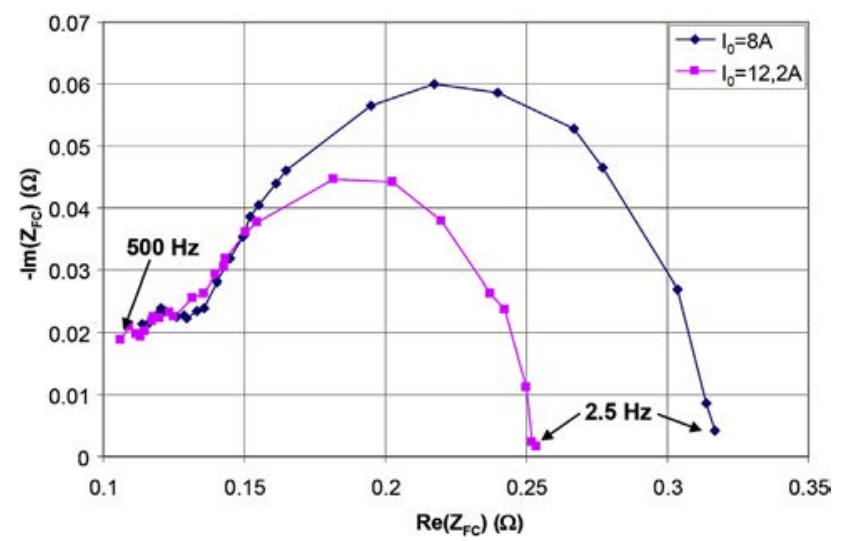

Fig. 10 - PEMFC impedance spectrum for load current variation. measurements of EIS for three levels of air humidity. The other test conditions are kept constant in order to observe the response of the PEMFC to membrane humidification changes only (constant flow and temperature of hydrogen, constant PEMFC temperature). Two sets of measurements are made for load currents $I_{0}=8 \mathrm{~A}$ and $I_{0}=12 \mathrm{~A}$ respectively shown in Fig. $11 \mathrm{a}$ and $\mathrm{b}$. As expected, the results show a reduction of the PEMFC impedance when the membrane humidification rate increases, and that both for low and high frequencies.

\section{Hydrogen flow rate effect}

The need for hydrogen depends on the energy demand at the electrical side of the PEMFC [28]. Hydrogen is the fuel of the PEMFC and it is necessary to optimally adjust its flow to maximize the efficiency of fuel cell electric generator. Although it is theoretically possible to determine the required hydrogen quantity by the stoichiometric relations, it is difficult to accurately assess the characteristics of the electrochemical reaction. Indeed, some properties of the PEMFC can change with unknown external conditions or over time with aging [29]. Energy demand can also vary over time and according to the control law of the DC bus voltage. The control of hydrogen flow rate is performed with an accuracy which depends on the reactivity of PEMFC auxiliaries [30]. Experimental results of Fig. 12 illustrate the influence of the hydrogen flow rate on the PEMFC impedance. The tests are performed under stable temperature and humidity conditions for a load current of $I_{0}=8 \mathrm{~A}$ and three overstoichiometric hydrogen flow rates $\left(\mathrm{Q}_{\mathrm{H}_{2}}=2.72 \mathrm{slpm}\right.$, 4.09 slpm and 5.45 slpm).

\section{Conclusion}

This work evaluates a solution of integration of PEMFC EIS functionality directly inside the existing power converter and control system. The experimental results validate the ability of the device developed in the laboratory to perform reliably EIS of the PEMFC. Operating process is defined to be compliant with using of the fuel cell in hybrid electric embedded systems. The power converter based on a high frequency transformer is an innovative solution to address the problem of integration issues and the need for significant elevation of PEMFC voltage for connection to the electric vehicle DC bus. The main advantages of this work are the full integration of EIS algorithms in the controller typically used for power control, and very low additional equipment required by the implementation of EIS measurements. The EIS process exploits the sensors and the microcontroller already used for power converter control. Then, the cost of EIS implementation is negligible and integration constraints are minimized. Integrating EIS functionality within the fuel cell system makes possible the development of on-board integrated diagnostic strategies. Embedded EIS of PEMFC can be performed during the power management, what makes possible the real time using of EIS results for real time diagnosis strategies to improve the conditions of use of PEMFC and to increase its life time without any increase of its cost. 

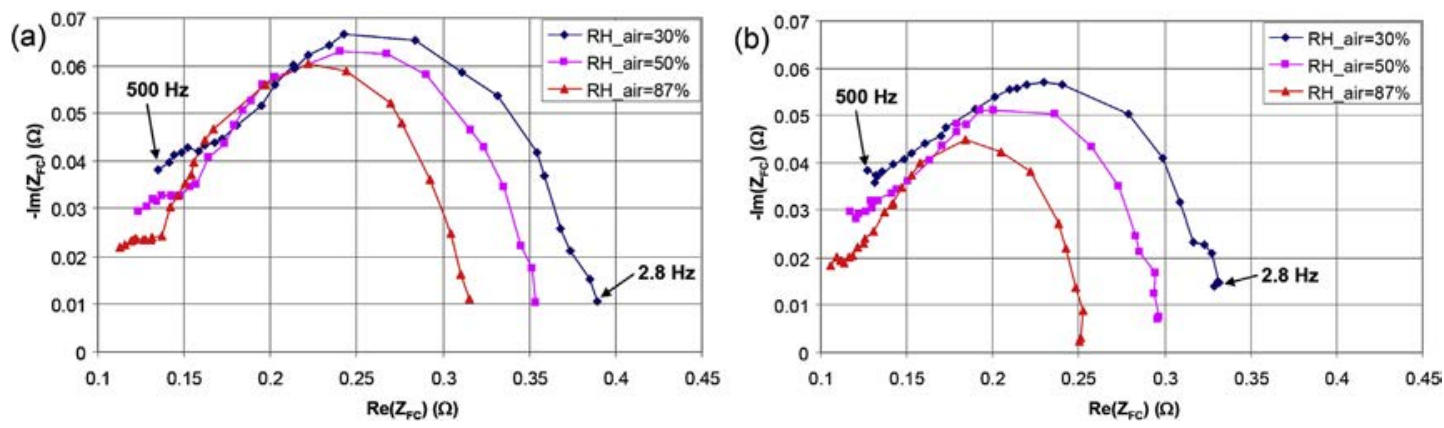

Fig. 11 - PEMFC impedance spectrum for air humidification variation $\left(Q_{H_{2}}=5.47\right.$ slpm, $\left.T_{F C}=48{ }^{\circ} \mathrm{C}, R_{-} H_{2}=20 \%\right)$. (a). $\mathrm{I}_{0}=8 \mathrm{~A}$. (b) $\mathrm{I}_{0}=12 \mathrm{~A}$.

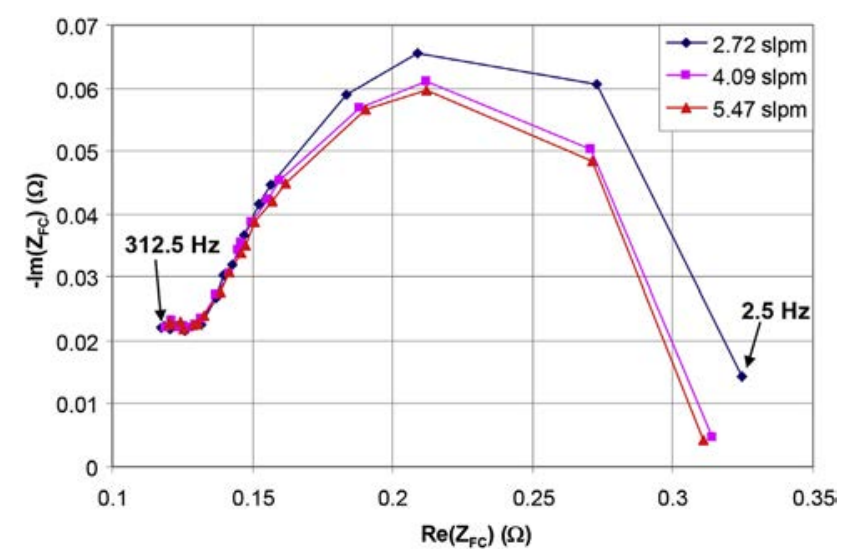

Fig. 12 - PEMFC impedance spectrum for hydrogen flow rate variation $\left(\mathrm{I}_{\mathrm{O}}=8 \mathrm{~A}, \mathrm{~T}_{\mathrm{FC}}=48{ }^{\circ} \mathrm{C}, \mathrm{RH}_{-}\right.$air $=87 \%$, RH_H $\left.H_{2}=20 \%\right)$.

\section{R E F E R E N C E S}

[1] Durbin DJ, Malardier-Jugroot C. Review of hydrogen storage techniques for on board vehicle applications. Int J Hydrogen Energy 13 November 2013;38(34):14595-617.

[2] Larriba T, Garde R, Santarelli M. Fuel cell early markets: techno-economic feasibility study of PEMFC-based drivetrains in materials handling vehicles. Int J Hydrogen Energy 19 February 2013;38(5):2009-19.

[3] Chevalier S, Trichet D, Auvity B, Olivier JC, Josset C, Machmoum M. Multiphysics DC and AC models of a PEMFC for the detection of degraded cell parameters. Int J Hydrogen Energy 30 August 2013;38(26):11609-18.

[4] Narjiss A, Depernet D, Gustin F, Hissel D, Berthon A. Design of a high efficiency fuel cell DC/DC converter dedicated to transportation applications. ASME J Fuel Cell Sci Technol November 2008;5.

[5] Gerard M, Poirot-Crouvezier J-P, Hissel D, Péra M-C. Ripple current effects on PEMFC aging test by experimental and modeling. J Fuel Cell Sci Technol Nov. 2010;8:0210041-021004-5.

[6] Park H. Numerical assessment of liquid cooling system for power electronics in fuel cell electric vehicles. Int J Heat Mass Transf June 2014;73:511-20.

[7] Depernet D, Gustin F, Hissel D. High efficiency DC/AC/DC converter based on synchronous rectifier for proton exchange membrane fuel cells. In: International conference on fundamentals and development of fuel cells 2015 FDFC2015; Feb. 03-05, 2015. Toulouse, France.

[8] Moçotéguy P, Ludwig B, Steiner N. Influence of ageing on the dynamic behaviour and the electrochemical characteristics of a 500 We PEMFC stack. Int J Hydrogen Energy 24 June 2014;39(19):10230-44.

[9] Nagahara Y, Sugawara S, Shinohara K. The impact of air contaminants on PEMFC performance and durability. J Power Sources August 2008;182:422-8.

[10] St-Pierre J. PEMFC contaminant tolerance limit - foreign cations in ionomers. Int J Hydrogen Energy May 2011;36(9):5527-35.

[11] St-Pierre J. PEMFC contaminant tolerance limit-CO in H2. Electrochimica Acta 1 May 2010;55(13):4208-11.

[12] Lopes T, Paganin VA, Gonzalez ER. The effects of hydrogen sulfide on the polymer electrolyte membrane fuel cell anode catalyst: H2S-Pt/C interaction products. J Power Sources August 2011;196:6256-63.

[13] Shi W, Yi B, Hou M, Jing F, Ming P. Hydrogen sulfide poisoning and recovery of PEMFC Pt-anodes. J Power Sources 20 March 2007;165:814-8.

[14] Shi W, Yi B, Hou M, Shao Z. The effect of H2S and CO mixtures on PEMFC performance. Int J Hydrogen Energy December 2007;32(17):4412-7.

[15] Garcia AC, Paganin VA, Ticianelli EA. CO tolerance of PdPt/C and PdPtRu/C anodes for PEMFC. Electrochimica Acta 1 May 2008;53(12):4309-15.

[16] Huang C-Y, Chen Y-Y, Su C-C, Hsu C-F. The cleanup of CO in hydrogen for PEMFC applications using Pt, Ru, Co, and Fe in PROX reaction. J Power Sources 22 November 2007;174:294-301.

[17] Depernet D, Ba O, Berthon A. Online impedance spectroscopy of lead acid batteries for storage management of a standalone power plant. J Power Sources 1 December 2012;219:65-74.

[18] Petrone R, Zheng Z, Hissel D, Péra MC, Pianese C, Sorrentino M, et al. A review on model-based diagnosis methodologies for PEMFCs. Int J Hydrogen Energy 10 June 2013;38(17):7077-91.

[19] Zheng Z, Petrone R, Péra MC, Hissel D, Becherif M, Pianese C, et al. A review on non-model based diagnosis methodologies for PEM fuel cell stacks and systems. Int J Hydrogen Energy 17 July 2013;38(21):8914-26.

[20] Cervera TG, Vega-Leal AP, García GA, Sánchez JB. PEMFC impedance spectroscopy using synthetic wide-band signals. Int J Hydrogen Energy 6 March 2014;39(8):4005-8.

[21] Yuan X, Wang H, Sun JC, Zhang J. AC impedance technique in PEM fuel cell diagnosis. Int J Hydrogen Energy December 2007;32(17):4365-80. 
[22] Hong P, Li J, Xu L, Ouyang M, Fang C. Modeling and simulation of parallel DC/DC converters for online AC impedance estimation of PEM fuel cell stack. Int J Hydrogen Energy 30 January 2016;41(4):3004-14.

[23] Zhang Z, Hu C. System design and control strategy of the vehicles using hydrogen energy. Int J Hydrogen Energy 13 August 2014;39(24):12973-9.

[24] Xu L, Ouyang M, Li J, Yang F, Lu L, Hua J. Application of Pontryagin's Minimal Principle to the energy management strategy of plugin fuel cell electric vehicles. Int J Hydrogen Energy 12 August 2013;38(24):10104-15.

[25] Zheng Z, Péra MC, Hissel D, Becherif M, Agbli KS, Li Y. A double-fuzzy diagnostic methodology dedicated to online fault diagnosis of proton exchange membrane fuel cell stacks. J Power Sources 20 December 2014;271:570-81.

[26] Zhiyu Y, Tao X, Zhixiang L, Yun P, Weirong C. Study on aircooled self-humidifying PEMFC control method based on segmented predict negative feedback control. Electrochimica Acta 20 June 2014;132:389-96.
[27] Kim S, Hong I. Effects of humidity and temperature on a proton exchange membrane fuel cell (PEMFC) stack. J Industrial Eng Chem May 2008;14(3):357-64.

[28] Han J, Park Y, Kum D. Optimal adaptation of equivalent factor of equivalent consumption minimization strategy for fuel cell hybrid electric vehicles under active state inequality constraints. J Power Sources 1 December 2014;267:491-502.

[29] Rohendi D, Majlan EH, Mohamad AB, Daud WRW, Kadhum AAH, Shyuan LK. Effects of temperature and backpressure on the performance degradation of MEA in PEMFC. Int J Hydrogen Energy 14 September 2015;40(34):10960-8.

[30] Kim S, Shimpalee S, Van Zee JW. The effect of stoichiometry on dynamic behavior of a proton exchange membrane fuel cell (PEMFC) during load change. J Power Sources 3 September 2004;135:110-21. 